\title{
Análise dos Conceitos de poder Disciplinar e Biopoder em Foucault
}

Maria do Socorro Cecílio Sobral ${ }^{1}$; Sidney Medeiros de Oliveira ${ }^{2}$

Resumo: O presente trabalho é uma resenha da obra "Foucault, para além do poder disciplinar e do biopoder" de Thamy Pogrebinschi. Escreve sobre um dos maiores filósofos contemporâneos, sobre as categorias do poder disciplinar e do biopoder, cujo argumento versa sobre a diferenciação do poder da idéia de repressão , de lei, aproximando-o de algo mais produtivo, positivo e emancipatório.

Palavras Chaves: Poder. Emancipação. Foucault.

\section{Analysis of Power Discipline and Biopower Concepts in Foucault}

\begin{abstract}
This paper is a review of the book "Foucault, beyond the disciplinary power and biopower" of Thamy Pogrebinschi. Write aboutone of the greatest contemporary philosophers, on the categories of disciplinary power and biopower, whose argument deals with thedifferentiation power of the idea of epression, law, bringing it to something more productive, positive and emancipatory.
\end{abstract}

Key words: Power. Emancipation. Foucault.

\section{Dados Sobre a Obra}

Michel Foucault (1926-1984) nasceu em Poitiers na França. Foi um filosofo Francês, diplomado em filosofia e psicologia. Lecionou filosofia em algumas Universidades francesas, obtendo a cátedra sobre a História dos sistemas de pensamento, no Collège de France. A autora Thamy Progrebinschi é professora de ciência política do Instituto de Estudos Sociais e Políticos da Universidade Estadual do Rio de Janeiro. Trata-se de um artigo publicado em 2004, pela Lua Nova, Revista de Cultura e Política, número 63, São Paulo.

\section{Análise dos Conceitos de Poder Disciplinar e Biopoder em Foucault}

A autora, inicia o trabalho expressando que Foucaut, mesmo sem dedicar especialmente um livro ao tema do poder, debruçou-se sobre as questões da loucura e da sexualidade, sobre as prisões ou os asilos, jamais deixando de preocupar-se com o referido tema.

\footnotetext{
${ }^{1}$ Graduada em Ciências Biológicas pela Universidade Regional do Cariri. Pós graduada em Ensino de pela Universidade de Pernambuco e em Metodologia do Ensino Superior pela Universidade Católica de Pernambuco. Professora da Faculdade de Ciências Humanas do Sertão Central - Autarquia Educacional de Salgueiro- PE. Mestre pela Universidade Federal do Rio Grande do Sul. Contato: socorrosobral@bol.com.br;

${ }^{2}$ Graduado em Educação Física, doutorando em Ciências da Saúde pela Faculdade de Medicina do ABC - São Paulo.

E-mail: meolli@hotmail.com.
} 
Dois problemas abrangem a análise dos conceitos de poder disciplinar e biopoder em Foucaut. O primeiro problema refere-se a um equívoco em torno dos conceitos destes dois tipos de poder, o segundo refere-se a um equívoco relativo ao conteúdo próprio e específico do conceito foucautiano de poder, que não se confunde nem com o poder disciplinar, nem com o biopoder.

A autora utiliza uma metodologia mais focada no primeiro período da obra de Foucaut (ou fase genealógica), deixando de lado uma análise da segunda fase (a hermêutica do sujeito).

Quanto à fase genealógica do poder, a autora refere algumas preocupações metodológicas. A primeira sobre o princípio da localidade, o que faz com que o poder seja analisado em suas formas e em suas instituições mais locais. O segundo seria a exterioridade ou a objetivação, o que significa buscar o poder naquele exato ponto, no qual ele se estabelece e produz efeitos. A terceira preocupação, seria sobre a circularidade ou transitoriedade, onde o poder circula sem se deter nas mãos de ninguém. A quarta, seria a ascenso. Neste caso,, percebe-se uma análise ascendente do poder, que parte de seus mecanismos moleculares e infinitesimais, até chegar àqueles mais gerais e globais. A ultima diz respeito a uma não - ideologização, onde o filósofo busca substituir, no lugar das ideologias, os saberes.

Parece ser contrário às hipóteses economicistas de "poder de Reich", abordagem jurídica ou de "contrato - opressão" e, parece também contra a "hipótese de Nietzsche", conhecida como abordagem maxista ou de "guerra - repressão".

O poder estaria entre o direito e a verdade. Segundo Thamy, Foucaut tenta afastar a hipótese repressiva substituindo uma teoria de "poder", por uma teoria "analítica" do poder. Dizendo: "No pensamento e na análise política, ainda não cortaram a cabeça do rei". Atribui a esse fato, a associação do poder com a repressão. Norma proibitiva de caráter negativo, gerando uma visão jurídica do poder, que só seria rompida com o corte da cabeça do rei.

Afastada a hipótese repressiva, pode-se caracterizar o poder foucautiano em seu aspecto mais positivo, identificando-se aí, pelo menos cinco características:

1- positividade: "temos que deixar de descrever sempre os efeitos de poder em termos negativos";

2 - imaterialidade: o poder está, ao mesmo tempo, em toda parte e em lugar nenhum;

3 - imanente; o poder não se encontra numa posição de exterioridade das coisas outras tais como o saber e o sexo;

4 - não subjetivo: o poder é passível de titularidade;

5 - não dualístico: o poder não se apoia em oposições binárias do tipo “ dominadores versus dominados, entre outras".

Thamy Pobrebinschi expressa que, conforme a pesquisa de Foucaut, ao longo dos séculos XVII e XVIII, muitas transformações ocorreram nas relações de poder. Uma das mais importante foi a 
substituição gradativa do poder da soberania, pelo poder disciplinar. Nesse ponto multiplicaram-se por todo corpo social, verdadeiras instituições disciplinares com a função de adestrar através do contrato. Este, um instrumento jurídico, onde os indivíduos cedem seu poder ao soberano por meio de um pacto.

Na concepção marxista, isso ressalta a "funcionalidade econômica do poder", isto é, mantêm as relações de produção e reproduzem a dominação de classe, operada pelo capitalismo. Além da multiplicação das instituições de disciplina, Foucaut observou que houve uma efusão de dispositivos disciplinares, pois a disciplina é um tipo de poder que faz aumentar a produção e o saber.

Quanto aos dispositivos disciplianares, os principais seriam três: o olhar hierárquico - que consiste na ideia de vigilância, em substituição a violência e a força; a sansão normalizadora - que traz consigo uma maneira de punir pela norma, substituindo a lei no regime do poder da soberania e, finalmente, o exame - que consiste em articular a vigilância e a sansão normalizadoras, fazendo o funcionamento das relações de poder, que permitiriam obter saber. $\mathrm{O}$ indivíduo passa a ser ao mesmo tempo, efeito e objeto do poder e do saber. Todos os dispositivos disciplinares funcionam como um laboratório de poder, integrando novas tecnologias , que representam o biopoder.

Na segunda metade do século XVIII, o poder disciplinar passar a ser complementado pelo biopoder, podendo coexistir no mesmo tempo e no mesmo espaço. Há muitas as variações entre as duas mecânicas do poder em questão. O poder disciplinar se faz sentir nos corpos dos indivíduos. O biopoder aplica-se em suas vidas.

Enquanto a disciplina promove a individualização dos homens, o biopoder acarreta a massificação. Daí os efeitos do biopoder serem sentidos em processos de conjuntos, coletivos, globais...que fazem parte da vida de uma população: os nascimentos, as doenças, as mortes, as taxas de fecundidade de uma população entre outros exemplos para explicar essa modalidade de poder. Em todos esses processos é importante perceber que o biopoder, produz saberes.

Entram em campo as ciências exatas e biológicas, que necessitam de demografias, políticas de natalidade, soluções para endemias, higiene e medicina e, com elas, podemos pensar que o biopoder assume, de certa forma, um poder de polícia com novos mecanismos. Os da previdência, ou prevenção, sinalizando preocupação com a otimização da vida e, uma maximação de forças convertidas em regulamentação, de forma a garantir a vida e evitar a morte. Ressalta-se que essa regulamentação não é exclusiva do Estado.

Poder disciplinar e biopoder, afinal, sobrepõem-se e superpõem-se constantemente e incessantemente. O melhor exemplo que Foucaut fornece entre essas duas modalidades de poder é a questão da sexualidade, com importância estratégica no século XIX, tendo em vista que dependia, simultaneamente de processos disciplinares e biológicos, individualizantes e massificantes, controladores e regulamentadores. Enfim, a sexualidade se situaria entre os corpos dos indivíduos singulares e, a unidade múltipla da população. A medicina , assim como a sexualidade, possuem tanto 
efeitos disciplinares como efeitos regulamentadores. Esses transitaria um elemento comum: a norma. Que pode tanto -se a um corpo que se quer disciplinar, quanto a uma população que se quer regulamentar.

O poder disciplinar e o biopoder operam como categorias historicamente constituídas , são as chaves de análise e interpretação do poder. Servem para que se crie um novo conceito de poder, cujo conteúdo o torna o produtivo, positivo e especialmente emancipatório. Com estreita relação com o saber.

Poder e saber se produzem e auto-reproduzem, estabelecendo uma relação de mútua dependência - e de mútua interdependência, produzindo, dessa fusão interprodutiva, um novo conceito: o poder-saber.

\section{Referências:}

PROGREBINSCHI, Thamy. Foucault, para além do poder disciplinar e do biopoder. Disponível Biografia de Michel Foucault. Disponível em <http://www.e-biografias.net/michel_foucault/>. Acesso em jan. 2016.

\section{Como citar este artigo (Formato ABNT):}

SOBRAL, Maria do Socorro C. OLIVEIRA, Sidney M. Análise dos conceitos de Poder Disciplinar e Biopoder em Foucault. Id on Line Revista de Psicologia, Fevereiro de 2016, vol.10, n.29, p. 160-163. ISSN 1981-1189.

Recebido: $15 / 01 / 2016$

Aceito: 02/02/2016 